\title{
Glomuvenous malformation
}

INSERM

\section{Source}

INSERM. (1999). Orphanet: an online rare disease and orphan drug data base.

Glomuvenous malformation. ORPHA:83454

Glomuvenous malformations (GVMs) are hereditary vascular malformations

characterized by the presence of small, multifocal bluish-purple venous lesions involving the skin. 